\title{
Nematode Management for Golf Courses in Florida ${ }^{1}$
}

\author{
William T. Crow ${ }^{2}$
}

Golf contributes to the quality of life of many residents and visitors to the state of Florida and generates billions of dollars for our state economy. Some of the criteria that are used to designate a good course are speed and evenness of the playing surface, and green, healthy grass. Each of these quality parameters can be negatively affected by plant-parasitic nematodes (Figure 1). Of all the pests that commonly affect golf course turf in Florida, nematodes are probably the least understood and most difficult to manage. Nematode problems are more common and more severe in

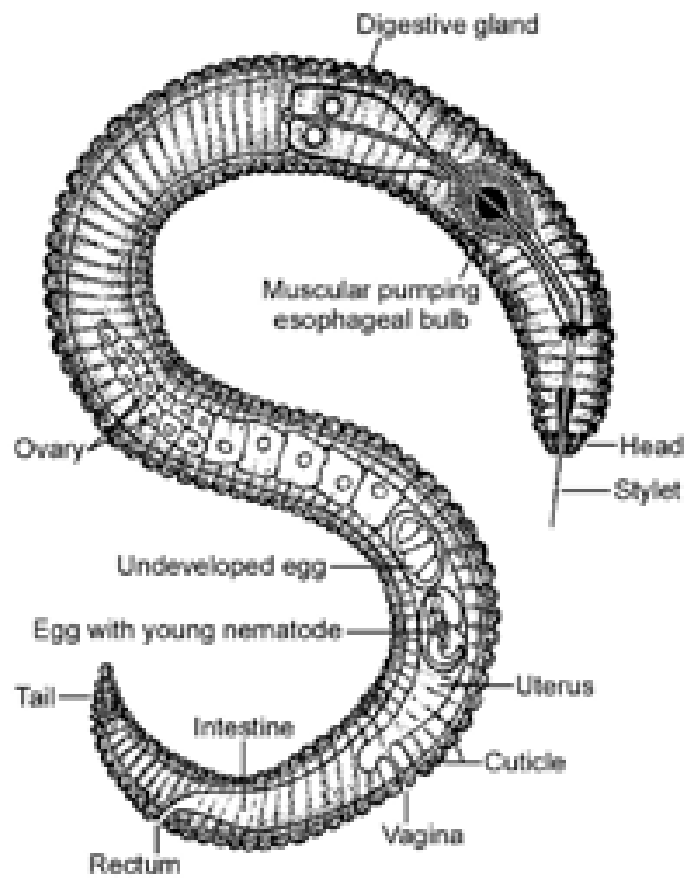

Figure 1. Diagram of a typical plant-parasitic nematode.
Florida than in most other states because our climate and soils provide a perfect habitat for many of the most destructive nematode species.

\section{What Are Plant-Parasitic Nematodes?}

Nematodes are unsegmented roundworms. Not all nematodes are bad; in fact, most species are beneficial, feeding on bacteria, fungi, or other microscopic organisms. There are even nematodes that can be used as biological control organisms to help manage important turf insect pests. However, there also are genera of nematodes that are pests or pathogens of animals or plants. Nematodes that feed on plants are called plant-parasitic nematodes. Plant-parasitic nematodes are very small, and microscopes are required to see them (Figure 2).

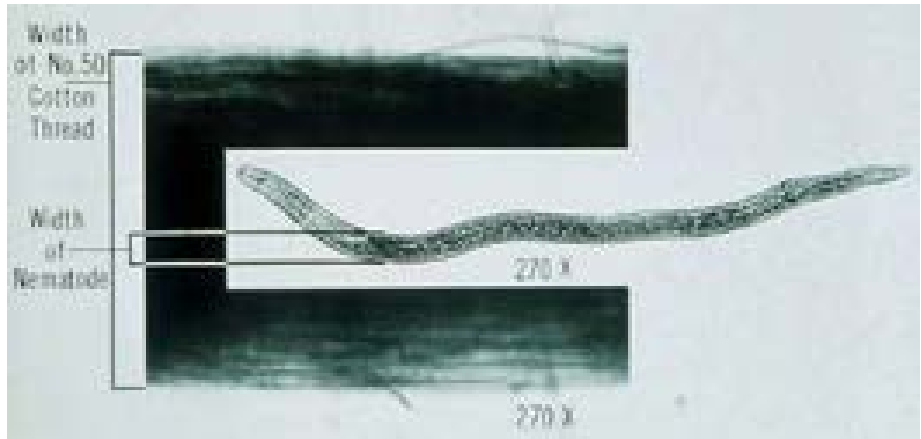

Figure 2. Size comparison of a typical plant-parasitic nematode to a cotton thread.

1. This document is ENY-008 (IN124), one of a series of the Entomology and Nematology Department, Florida Cooperative Extension Service, Institute of Food and Agricultural Sciences, University of Florida. First published: February 2001. Revised: March 2011 and January 2013. For more publications related to horticulture/agriculture, please visit the EDIS website at http://edis.ifas.ufl.edu/.

2. William T. Crow, associate professor, Entomology and Nematology Department, Cooperative Extension Service, Institute of Food and Agricultural Sciences, University of Florida, Gainesville, 32611. 
Plant-parasitic nematodes have a stylet or mouth-spear that is similar in structure and function to a hypodermic needle (Figure 3 ). The stylet is used to puncture plant cells, and then the nematode can inject digestive juices and ingest plant fluids through it. Plant-parasitic nematodes are grouped by how they feed on plants.

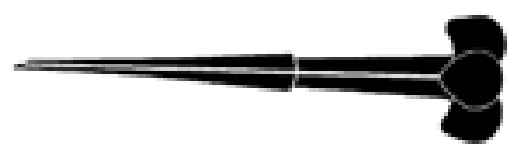

Figure 3. A typical plant-parasitic nematode stylet resembles a hypodermic needle.

Ectoparasites are species that feed by inserting just their stylet into roots while their body remains outside in the soil (Figure 4). Because they spend their entire life in the soil, contact nematicides can work well for these nematodes. Some common genera of ectoparasitic nematodes that damage turf in Florida are sting nematode (Belonolaimus), stubby-root nematodes (Trichodorus and Paratrichodorus), and ring nematodes (Mesocriconema).

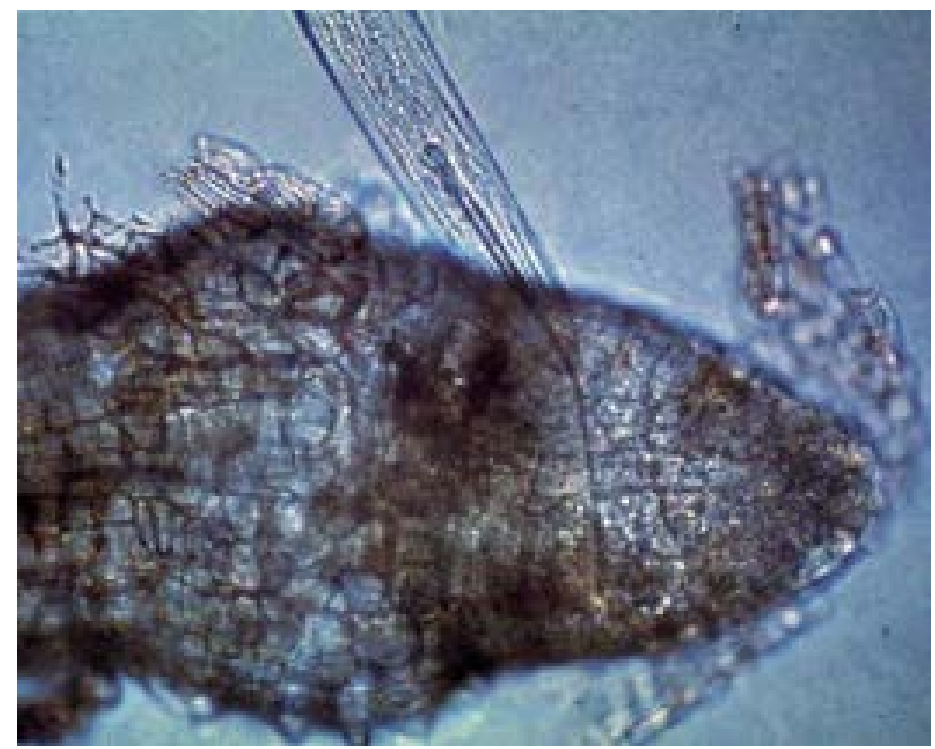

Figure 4. An ectoparasitic nematode feeding by inserting its stylet into a root tip.

Migratory endoparasites are nematode species that enter into plant tissue with their body and tunnel around, feeding as they move from cell to cell (Figure 5). As they tunnel through plant roots they disrupt the vascular tissues and prevent roots from functioning properly. These nematodes typically lay their eggs within roots. Because the nematodes and their eggs are largely within roots, systemic nematicides usually work best against migratory endoparasitic nematodes. The most common genera of migratory endoparasites that affect turf in Florida are lance nematodes (Hoplolaimus).

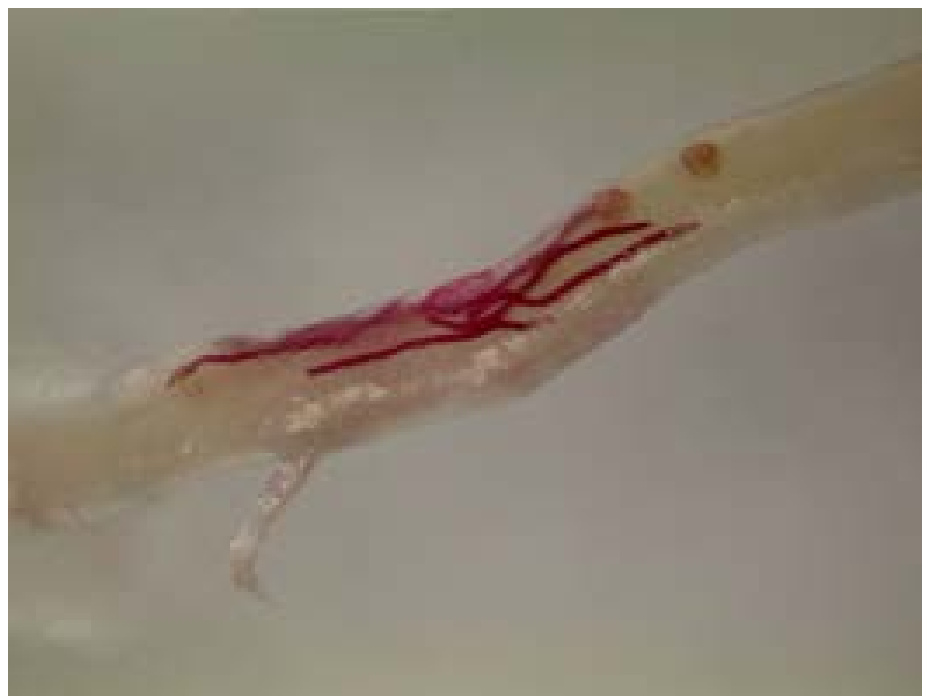

Figure 5. Endoparasitic nematodes burrowing within a root.

Sedentary endoparasites are nematodes that enter into roots and then inject hormones that cause specialized feeding sites to develop. After initiating a feeding site, these nematodes will no longer move and will lose their typical worm-like shape. Females become round or pear-shaped (Figure 6). Eggs are laid in egg masses that can contain several hundred eggs per egg mass. The egg masses may occur within the root tissue, or be exposed at the root surface. While systemic nematicides typically are more effective for sedentary endoparasites, contact nematicides can affect eggs exposed at the root surface. The most common genera of sedentary endoparasites on turf in Florida are the root-knot nematodes (Meloidogyne).

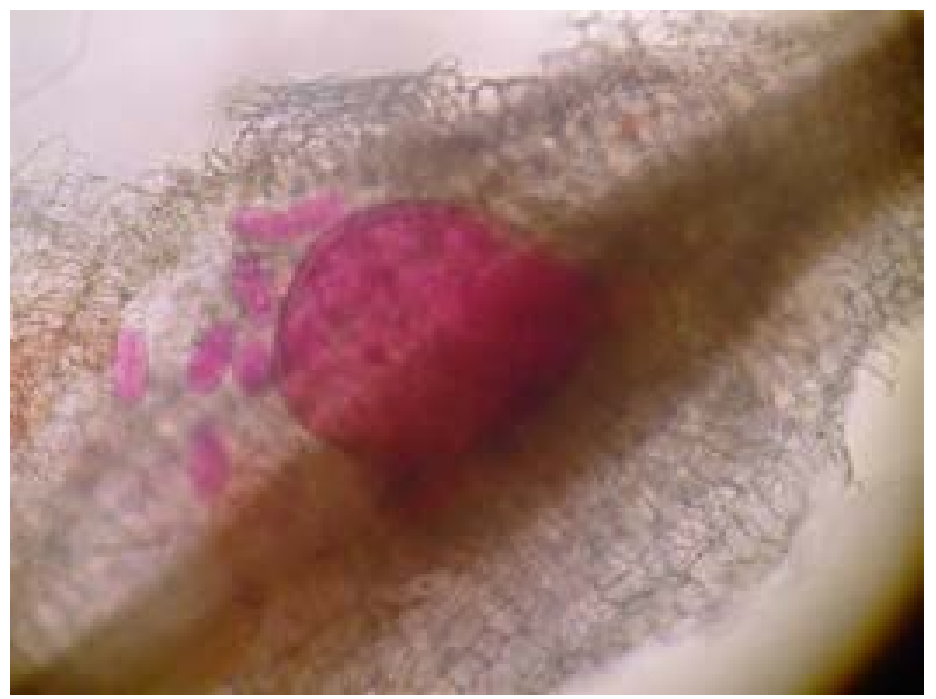

Figure 6. Female root-knot nematode laying eggs inside a bermudagrass root. The nematode and eggs are stained red. 


\section{How Do Nematodes Affect Turf?}

As plant-parasitic nematodes feed, they damage the root system and reduce the ability of the plant to obtain water and nutrients from the soil. Ectoparasites usually cause roots to be short and stubby (Figure 7). Endoparasites often cause roots to be dark and rotten-looking (Figure 8). Both ecto- and endoparasites cause a reduction in the fine feeder-roots that are important in water and nutrient uptake by the plant. The root galls or knots associated with certain nematode damage to other crops are usually not evident on grasses, but may occur in some cases.

When nematode population densities get high enough, or when environmental stresses occur, above-ground symptoms may become evident. Symptoms include yellowing, wilting, thinning, or death (Figure 9). Plant-parasitic nematodes usually occur in clumps, so nematode damage usually occurs in irregularly shaped patches that may enlarge slowly over time. Often, as the grass thins, weeds such as spurge may become prominent (Figure 10). This is because the nematode-damaged grass is less competitive with the weeds.

Research has shown that nematode-damaged turf roots are less able to get water and nutrients from soil. Nematodedamaged turf typically needs frequent irrigation to avoid wilting and decline. Also, the potential for nutrient leeching is higher from nematode-damaged turf.

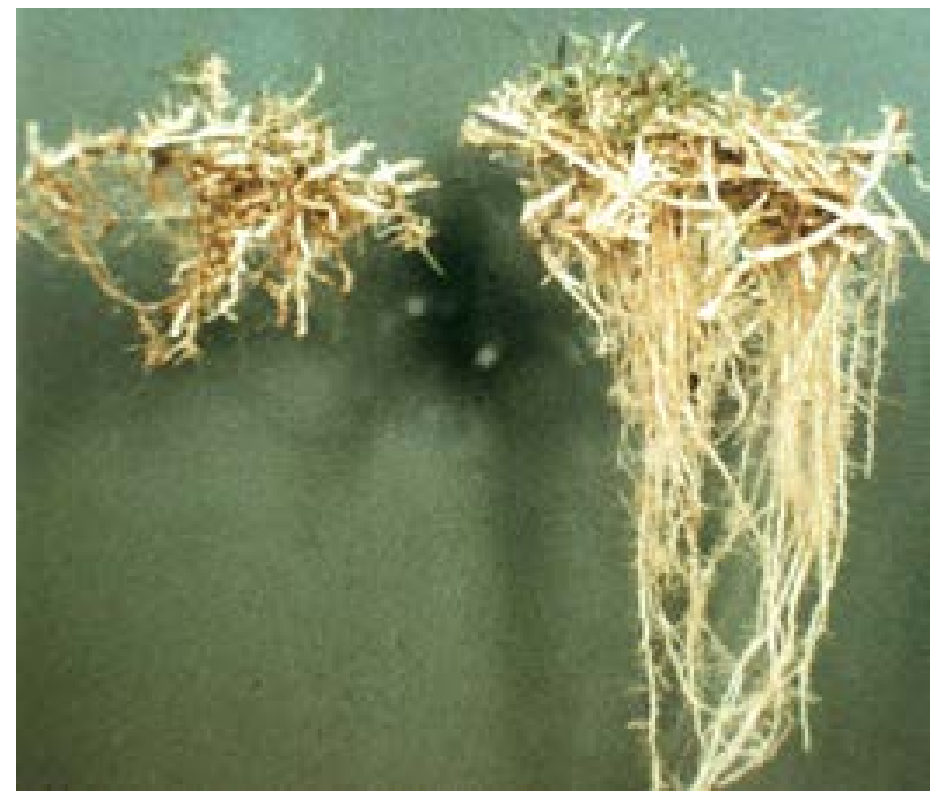

Figure 7. Healthy bermudagrass roots (right) and roots that have been cropped off at about 1/2 inches deep by nematodes (left).

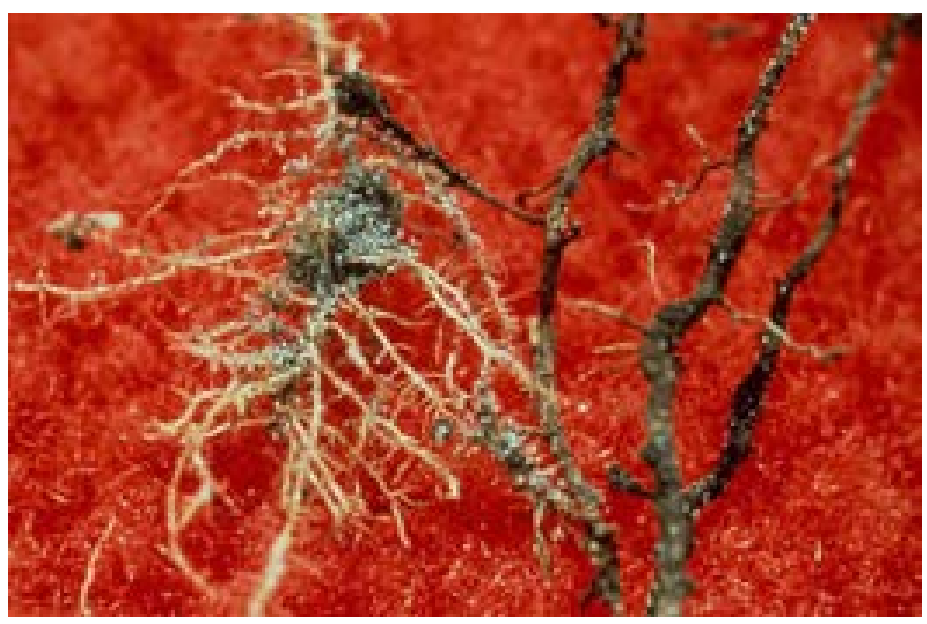

Figure 8 . Healthy grass roots (left) and dark, rotting grass roots damaged by nematodes.

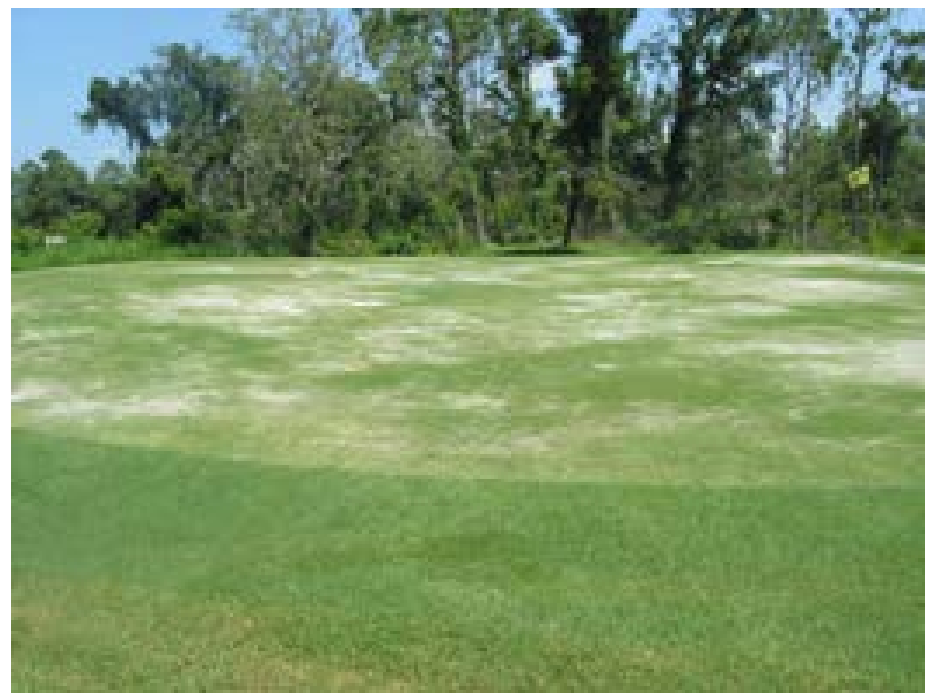

Figure 9. Severe nematode damage on a bermudagrass putting green.

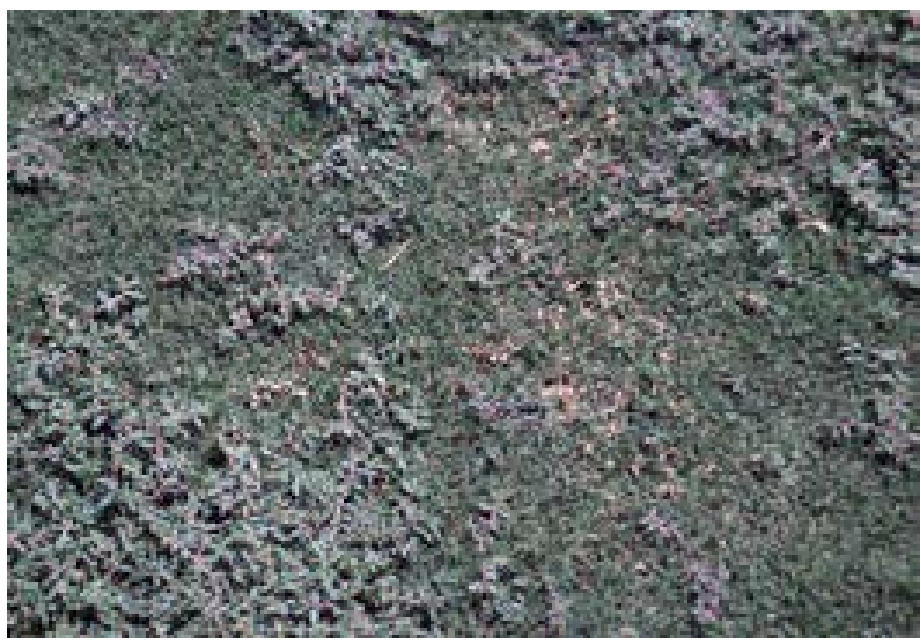

Figure 10. Turf decline caused by nematodes is often accompanied by proliferation of spurge. 


\section{How Do I Know If Nematodes Are A Problem?}

With any plant problem, having an accurate diagnosis is important to address the problem and to avoid wasting time, money, effort, and unnecessary pesticide applications. The only reliable way to determine if plant-parasitic nematodes are involved in a grass problem is by having a nematode assay conducted by a professional nematode diagnostic lab. The University of Florida has such a facility and will assay nematode samples for a cost of $\$ 20$ each (out-of-state samples cost $\$ 25$ each). Forms and instructions for submitting nematode samples to the Florida Nematode Assay Lab can be downloaded at http://nematology.ifas.ufl.edu/assaylab.

A nematode assay is a separate procedure and requires different sampling guidelines than those required for soil analysis or disease samples. Be aware that when a disease sample is submitted to most labs a nematode analysis is not normally performed unless you specifically request it. A nematode assay often requires separate payment and may even be sent to a separate address. Familiarize yourself with the procedures required by the lab where you intend to submit the sample. The accuracy of the diagnosis depends on the quality of the sample that you submit. Following the guidelines below will help insure an accurate diagnosis:

1) A sample must consist of multiple cores. Nematodes are not evenly distributed in soil, but rather are clumped in distribution. A nematode population density may be high at one spot and low just a few feet way. By collecting multiple cores with a device such as a T-type soil probe or similar device, an average population density can be measured. A cup-cutter core is often adequate for a disease diagnosis, but not for nematode diagnosis. A good rule of thumb is to collect 16-20 1/2-inch-diameter cores per area (green, fairway, etc.).

2) If damage is evident, then sample near the margin of affected areas (Figure 11). Nematode populations will decline in severely damaged areas because they have nothing left to eat. Do not take samples from dead areas. Try and sample turf that is declining, but not dead.

When taking samples from turf that is not yet showing above-ground symptoms, or if sampling before planting, sample in a zig-zag pattern across the area (Figure 12).

3) Put the soil from each sampled area into a plastic bag and seal it. Nematodes require moisture to survive so drying the soil will kill them. This is different than submitting a sample

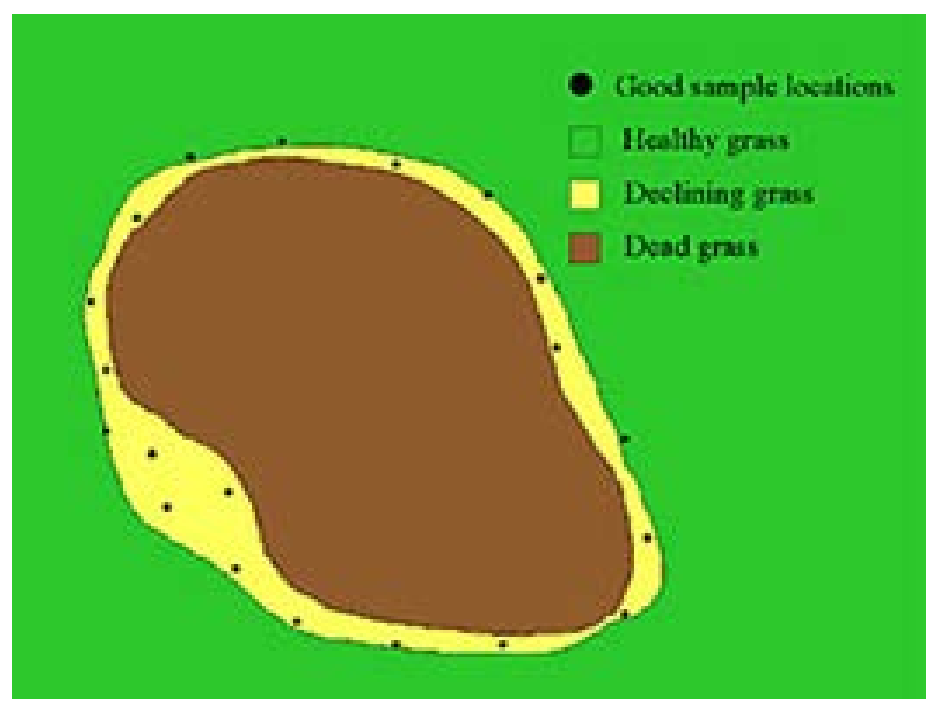

Figure 11. Collect cores for a nematode sample from the edges of declining areas.

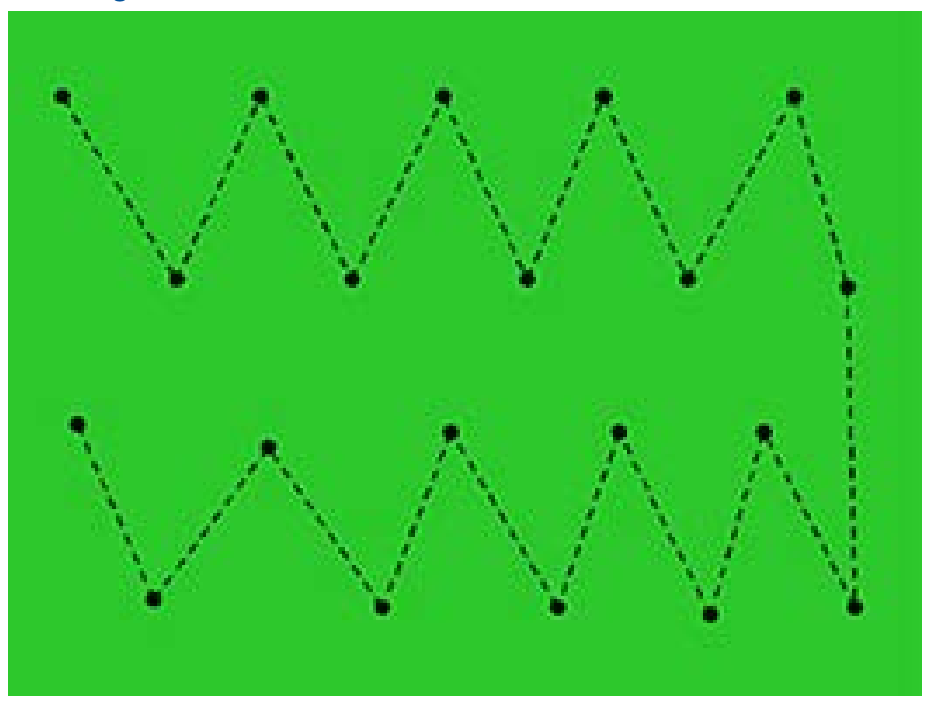

Figure 12. When sampling healthy appearing turf, collect cores in a zig-zag pattern across the area.

for nutrient analysis where dry soil is preferred. Make sure that each bag is labeled with a permanent marker so that the diagnosis can be assigned to the correct area. If using a ziplock type bag, seal it with tape because the zippers often come open in transit.

4) Handle samples carefully. Do not expose samples to direct sunlight or heat. Nematodes are sensitive to high temperatures and UV light. Leaving samples on the dashboard of your car or in the back of a golf cart for periods of time can kill them quickly and negatively affect the accuracy of the diagnosis. It is best to keep the nematodes samples in an air-conditioned room until shipping. For shipping and transport, pack the samples well so that shifting is minimized.

5) Submit the sample right away. Next-day delivery is best. One study found greatest nematode recovery from 
hand-delivered samples, the next highest from next-day delivery, and the lowest from regular postal delivery. Shipping samples early in the week is best in order to avoid having them sit in a warehouse or on a truck over the weekend.

The staff at the University of Florida Nematode Assay Lab will make a determination of how much risk of nematode damage the sampled turf is under based on which nematodes are found and how many of them there are. Turf from each sample will be assigned as having low, moderate, or high risk of damage occurring. Not all plant-parasitic nematodes are equal in their ability to harm grass. For example, one sting nematode can cause damage equal to hundreds of individuals of some other types of plant-parasitic nematodes. The current risk thresholds used for golf course turf in Florida are shown in Table 1.

Table 1. Risk Thresholds for Golf Course Turfgrasses in Florida.

\begin{tabular}{|c|c|c|c|c|c|c|}
\hline \multirow[t]{2}{*}{ Nematode Species } & \multicolumn{2}{|c|}{ Bermuda } & \multicolumn{2}{|c|}{ Zoysia } & \multicolumn{2}{|c|}{$\begin{array}{l}\text { Seashore } \\
\text { paspalum }\end{array}$} \\
\hline & M & $\mathbf{H}$ & M & $\mathbf{H}$ & $\mathbf{M}$ & $\mathbf{H}$ \\
\hline $\begin{array}{l}\text { Root-knot } \\
\text { (Meloidogyne) }\end{array}$ & 80 & 300 & 80 & 300 & 80 & 300 \\
\hline $\begin{array}{l}\text { Sting } \\
\text { (Belonolaimus) }\end{array}$ & 10 & 25 & 10 & 25 & 10 & 25 \\
\hline $\begin{array}{l}\text { Lance } \\
\text { (Hoplolaimus) }\end{array}$ & 40 & 120 & 40 & 120 & 40 & 120 \\
\hline $\begin{array}{l}\text { Stubby-root } \\
\text { (Paratrichodorus) }\end{array}$ & 150 & 300 & 150 & 300 & 150 & 300 \\
\hline $\begin{array}{l}\text { Stubby-root } \\
\text { (Trichodorus) }\end{array}$ & 40 & 120 & 40 & 120 & 40 & 120 \\
\hline $\begin{array}{l}\text { Spiral } \\
\text { (Helicotylendhus) }\end{array}$ & 700 & 1500 & 700 & 1500 & 300 & 700 \\
\hline $\begin{array}{l}\text { Spiral } \\
\text { (Peltamigratus) }\end{array}$ & 150 & 300 & 150 & 300 & 150 & 300 \\
\hline $\begin{array}{l}\text { Ring } \\
\text { (Mesocriconema) }\end{array}$ & 500 & 1000 & 500 & 1000 & 500 & 1000 \\
\hline $\begin{array}{l}\text { Sheath } \\
\text { (Hemicycliophora) }\end{array}$ & 150 & 300 & 150 & 300 & 150 & 300 \\
\hline $\begin{array}{l}\text { Sheathoid } \\
\text { (Hemicriconemoides) }\end{array}$ & 500 & 1000 & 500 & 1000 & 500 & 1000 \\
\hline $\begin{array}{l}\text { Awl } \\
\text { (Dolichodorus) }\end{array}$ & 10 & 25 & 10 & 25 & 10 & 25 \\
\hline \multicolumn{7}{|c|}{$\begin{array}{l}\text { Key: } \\
M=\text { Turf is considered at moderate risk of damage. Damage may } \\
\text { become evident if the turf is placed under stress conditions. } \\
\mathrm{H}=\text { Turf is considered at high risk of damage. Root systems are } \\
\text { likely damaged and turf quality may be declining. }\end{array}$} \\
\hline \multicolumn{7}{|c|}{$\begin{array}{l}\text { * These nematodes are based upon numbers per } 100 \text { cc of soil } \\
\text { extracted using a sugar-flotation with centrifugation method. } \\
\text { ** Other nematodes may damage turf in Florida, but damage from } \\
\text { these is very rare so thresholds are not listed. } \\
\text { ** These thresholds are based upon nematodes, grasses, and } \\
\text { conditions in Florida only. They may not apply in other states. }\end{array}$} \\
\hline
\end{tabular}

Be aware that different diagnostic labs may use different extraction techniques, use different quantities of soil, or use different thresholds. Because of this, samples submitted to separate labs may report different quantities of nematodes. Do not be alarmed by this; in most cases, the different thresholds used are adjusted to account for the differences in methodology and sample size.

\section{How Do I Manage Nematodes? Before Planting}

It is always preferable to avoid a potential problem than to deal with an existing one, so it is best to consider nematodes during course construction or reconstruction. Currently, chemical management of nematodes before planting is most commonly achieved by soil fumigation. Soil fumigation involves injecting a liquid or incorporating a granular material into the soil. The material then either converts to a gas or releases a gas that kills nematodes and other organisms. In addition to nematodes, many of the fumigants have activity against weeds and/or soilborne diseases and/or insects. Several soil fumigants are currently available for course construction and reconstruction. Currently the broad-spectrum fumigant methyl bromide (bromomethane) is the most commonly used fumigant in golf course construction and reconstruction. Because this fumigant has been identified as an ozone-depleting compound, it is currently being phased out worldwide. In the United States, existing stocks can still be used but the fumigant will become harder and harder to obtain. Researchers at the University of Florida continue to explore alternative fumigants.

Contaminated planting material (sod or sprigs) are a means whereby nematodes can be spread into new areas. Certified sod is generally not nematode-free. Before purchasing sod, it is sometimes a good idea to have the sod field sampled prior to purchase to detect the presence of the more damaging nematode species.

A key component of IPM is the use of resistant or tolerant plants. Research at the University of Florida has found that the dwarf bermudagrass cultivars Tifdwarf and Emerald Dwarf are more tolerant of sting nematodes than the ultradwarf cultivars evaluated. Similarly, the non-dwarf bermudagrass cultivars TifSport, Celebration, and Princess 77 were better at withstanding attack by sting nematode than were other cultivars evaluated. Generally speaking, the more vigorously rooting a cultivar, the more nematode tolerant it should be. 


\section{Established Turf \\ CULTURAL PRACTICES}

Plant-parasitic nematodes are often one of many stress factors affecting the health of turf. The nematodes may be a major contributing factor to turf stress, or a minor one. Often, reducing the overall stress level on turf can help the grass to counteract the negative effects of nematodes.

Mowing height: As a rule of thumb, the lower the grass is mowed, the greater the stress the grass is under. Research has shown that nematode-infested turf declines more readily at lower mowing heights. Often, raising mowing height slightly can reduce nematode damage considerably. With increased pressure by certain golfers to have increased ball speed, course superintendents face increased pressure to lower mowing height. Unfortunately, sometimes a choice must be made to sacrifice some ball speed in order to maintain turf on nematode-infested greens.

Fertility: Excessive nitrogen fertilization can increase succulent root growth and encourage rapid foliage growth. Succulent root tips are more susceptible to nematode damage, and the proliferation of root tips (nematode food) can cause nematode population densities to rise dramatically. Rapidly growing foliage drains nutrient reserves from the roots that are needed to compensate for the nematode damage. Under-fertilization should also be avoided. Roots damaged by nematodes will already have a reduced capability to extract nutrients from soil. This makes nutrient deficiencies more pronounced on nematode-infested plants.

Watering: Deep, infrequent watering encourages deep root growth. A deep root system is more tolerant of nematodes than a shallow root system resulting from shallow, frequent watering. However, once nematode damage is extensive, frequent light watering may be required to keep the grass from wilting. During times of extended drought, this can lead to buildup of salts and other problems, so periodic deep irrigation will still be required.

Compaction and aeration: Over-compaction reduces oxygen penetration to the root system and enhances susceptibility to nematode damage. Aeration encourages a healthy root system and thereby enhances tolerance to nematodes. In cases where certain greens are nematodeinfested and others are not, aerate the infested greens last to avoid transferring nematodes to the clean ones in soil adhering to aerification equipment.
Soil amendments: Generally, anything that promotes healthy root growth can enhance tolerance to nematodes. Incorporation of colloidal phosphate has been shown to enhance bermudagrass tolerance to several nematodes. Some organic amendments such as composted municipal sludge or composted manures may also reduce nematode damage and speed the recovery process after damage has occurred.

Shade: By damaging roots, nematodes impair the ability of turf to store energy. Therefore, nematode-damaged turf often is more prone to decline from shade, or prolonged poor weather. If greens are in partial shade, trimming or thinning trees to get more light to the turf will greatly enhance the turf's ability to withstand nematode damage.

Overseeding: UF research has shown that overseeding can increase nematode numbers on bermudagrass during transition by providing an alternate food source to the nematodes during the winter. Therefore, from a nematode management point of view it is best to avoid overseeding.

\section{BIONEMATICIDES}

Nortica: The active ingredient in Nortica ${ }^{\mathrm{Tn}}$ is the bacterium Bacillus firmus strain I-1582. This bacterium colonizes the root system of the turf and produces compounds that protect the root system from nematodes. Nortica is a wettable powder that disperses in water. It is sprayed onto the turf surface and then moved into the soil with irrigation. University of Florida research has shown this biological agent to be effective in protecting turfgrass roots from nematode damage when it is applied properly. However, to achieve good results, timing is critical with this product. An application map for Florida counties, available from Bayer Environmental Sciences at http://www.backedbybayer.com/ nortica, should be consulted when scheduling applications. Since Nortica has more of a root-protecting mode of action than a nematode-killing one, it works better when used in the early season to prevent a nematode problem than to "fix" an existing one in mid-season.

MustGrow Invest: MustGrow Invest is a bionematicide derived from certain mustard plants grown in Canada. These types of mustard contain high amounts of glucosinolates. When glucosinolates are acted on by enzymes, they produce a new chemical, allyl isothioscyanate or AITC, which is a nematicidal fumigant. MustGrow Invest is a granular product that is inert while it stays dry; the production of AITC begins once the product gets wet. For turf, MustGrow Invest is applied topically using a fertilizer spreader at rates of 15 to $20 \mathrm{lb} . / 1000 \mathrm{ft}^{2}$. The turf surface should be 
dry (no dew) at the time of application. After application, irrigate with an inch of water to move the glucosinolates into the soil so that the AITC forms underground where the nematodes occur. MustGrow Invest works best when an efficient irrigation system capable of applying a large amount of water in a short amount of time is used. If the irrigation system puts out water slowly, much of the AITC formed will dissipate into the air and be wasted. If puddling occurs, cease irrigation until the puddles drain and then begin irrigating again. Aerifying prior to application may aid movement of AITC into the soil. In addition to effects on nematodes, MustGrow Invest is a source of organic nitrogen and other plant nutrients. Because MustGrow Invest contains $5 \% \mathrm{~N}$, an application supplies 0.75 to $1.0 \mathrm{lb}$ of $\mathrm{N} / 1000 \mathrm{ft}^{2}$.

\section{CHEMICAL NEMATICIDES}

Even the best managed turf can suffer from nematode injury, requiring chemical intervention. Historically, most nematicides have been toxic at low levels and water soluble in order to move into the soil profile and kill nematodes. Many of the effective nematicides used in the past have been withdrawn from the market during the last 25 years for environmental and health reasons, so only a handful remain. When using any nematicide, the product label must be strictly adhered to in order to minimize human and environmental health impacts and to avoid liability. Nematicides labeled for golf course turf in Florida that have shown consistent efficacy in University of Florida research trials are discussed below. This information is not a substitute for the product label. Always follow directions on the product label when applying any pesticide.

Curfew Soil Fumigant: Curfew Soil Fumigant ${ }^{\mathrm{tm}}$ is different from most other turfgrass pesticides in that it is injected into the soil profile as a liquid that then volatilizes and moves through the soil as a gas (fumigant). The active ingredient in Curfew Soil Fumigant is 1,3-dichloropropene (1,3-D). Curfew Soil Fumigant cannot be applied by golf course staff, but may only be applied by approved custom applicators. Applications are scheduled through certain golf course industry distributors. While application equipment for greens is slightly different from that used on fairways, the application method is similar. Slits are made in the turf by knives that have a metal drip tube welded onto the back. As the knives are pulled through the soil, the fumigant is injected 5-6 inches deep into the soil profile, and the slits are then pressed back together to reduce fumigant loss. The 1,3-D turns into a gas that disperses through the soil profile and kills nematodes on contact.
Curfew Soil Fumigant is highly effective against sting nematode and other ectoparasites. It also is effective against mole crickets. However, because it is a contact nematicide, its efficacy against endoparasitic nematodes such as lance or root-knot nematodes is less consistent. Dow AgroSciences instructions for irrigation and turf care following a Curfew Soil Fumigant application should be followed closely to avoid problems and maximize the benefits of Curfew. Curfew cannot be applied within $30 \mathrm{ft}$ of buildings, and a 24-hour reentry restriction applies. In areas of Florida with certain geologic features, Curfew Soil Fumigant cannot be used.

Multiguard Protect: Multiguard Protect ${ }^{\oplus}$ EC is a turfgrass nematicide/fungicide with the active ingredient furfural. This is an EC formulation that can be sprayed onto turf and is then either moved into the soil with irrigation, or applied as a high-volume drench. University of Florida research has found that Multiguard Protect, when used properly, is effective against ectoparasitic nematodes, especially 2-6 inches deep in the soil profile. Typically, multiple applications applied at 2-3 week intervals are required for good results.

To avoid phytotoxicity, make sure the soil is moist; preirrigate if necessary. After applying Multiguard Protect, irrigate immediately with $1 / 4$-inch of water; do not irrigate again for at least 24 hours after application. Do not apply if significant rainfall is expected within 24 hours. While typically a positive turf response is observed following treatment with Multiguard Protect, University of Florida research has found that some turfgrass species and cultivars may be more sensitive to furfural than others. Because we have not evaluated furfural effects on all grasses, test treating small areas for grass response prior to treating large areas may be warranted.

Other Products: In order for University of Florida faculty to recommend a pest management product, data from properly conducted field research trials should indicate that the product works on a consistent basis. There are a several botanical nematicides and microbial products on the market. For most of these, either field efficacy data is lacking, or field trial data has not shown consistent benefit. That does not mean that these products never work, but that there is insufficient evidence to recommend their use.

\section{Summary}

Nematode management on a golf course can be a daunting task. Expectations for a pristine playing surface are high, and nematodes are notoriously difficult to control. The best management practices for golf courses with nematode 
problems are: 1) avoid other stresses on the grass as much as possible, 2) monitor nematode populations by sampling frequently, and 3) apply nematicides when needed.

The University of Florida is committed to bringing you the most current information possible. Consequently this document will be modified with each breaking development. The most current version of this document may be obtained online at the University of Florida's Electronic Document Information System (EDIS) website at http:// edis.ifas.ufl.edu/.

For additional information regarding nematodes, nematode management, or help interpreting nematode assay results contact:

\author{
William T. (Billy) Crow, Ph.D. \\ Associate Professor of Nematology \\ University of Florida \\ Entomology and Nematology Dept. \\ P.O. Box 110620 \\ Gainesville, FL 32611 \\ (352) 273-3941 \\ FAX (352) 392-0190 \\ E-mail: wtcr@ufl.edu
}

For information on submitting samples to the University of Florida Nematode Assay Lab or to check on the status of a sample you submitted, contact:

Nematode Assay Lab

Building 970, Natural Area Drive

P.O. Box 110620

Gainesville, FL 32611

(352) 392-1994

FAX (352) 392-0190

E-mail: nemalab@ifas.ufl.edu 